\title{
Clinical Reasoning: A 12-year-old girl with headache and change in mental status
}

Payal Patel, MD, Ahmara Ross, MD, PhD, Fredrick M. Henretig, MD, Grant Liu, MD, Brian Harding, MD, and Jessica Panzer, MD, PhD

Neurology ${ }^{\circledR}$ 2018;90:524-529. doi:10.1212/WNL.0000000000005116
Correspondence

Dr. Patel

Payal.b.patel@yale.edu

\section{Section 1}

A 12-year-old girl presented to the emergency department with headaches for 1 week in the setting of a 20-pound weight gain over the last year. Headaches were described as severe, throbbing, constant, and occipital, with photophobia, nausea, and vomiting. Pain was worse with standing.

\section{Neurologic examination}

The patient's visual afferent examination was unremarkable. Her efferent examination was notable for a -1 right abduction deficit and a small angle esotropia. Her ophthalmoscopic examination showed bilateral papilledema. Her visual fields showed scattered shallow defects in the right eye and a deep superior hemifield defect in the left eye that crossed the vertical midline. Her body mass index was $35 \mathrm{~kg} / \mathrm{m}^{2}$. The remainder of her general medical examination was normal and her neurologic examination was nonfocal.

\section{Questions for consideration:}

1. What is your differential diagnosis?

2. What further studies should be conducted?

\section{GO TO SECTION 2}

From the Department of Neurology, Department of Infectious Diseases (P.P.), Yale University, New Haven, CT; Departments of Ophthalmology (A.R.) and Neuro-ophthalmology (G.L.), Children's Hospital of Philadelphia; and Emergency Medicine, Poison Control Center (F.M.H.), Department of Pathology (B.H.), and Pediatric Neurology (J.P.), Children's Hospital of Philadelphia, PA.

Go to Neurology.org/N for full disclosures. Funding information and disclosures deemed relevant by the authors, if any, are provided at the end of the article. 


\section{Section 2}

Pseudotumor cerebri syndrome describes a potentially blinding condition from elevated intracranial pressure with normal brain parenchyma. The presence of papilledema is a hallmark of the disease; additional criteria include normal neurologic examination, with the exception of cranial neuropathies, normal brain parenchyma without evidence of hydrocephalus, mass, or meningeal enhancement, normal CSF composition, and elevated intracranial pressure. The CSF pressure is considered elevated if it is greater than $25 \mathrm{~cm}$ $\mathrm{H}_{2} \mathrm{O}$ in adults and $28 \mathrm{~cm} \mathrm{H}_{2} \mathrm{O}$ in children. Differential diagnoses of elevated intracranial pressure in children include idiopathic intracranial hypertension, cerebral venous thrombosis, and medication side effects, such as isotretinoin. ${ }^{1}$

Initial laboratory evaluation revealed a lumbar puncture opening pressure of $60 \mathrm{~cm} \mathrm{H}_{2} \mathrm{O}$ with a normal CSF profile. MRI with contrast and magnetic resonance venography were normal. The patient was started on $500 \mathrm{mg}$ of acetazolamide twice a day for presumed idiopathic intracranial hypertension and discharged home.

The patient returned 2 weeks after discharge with continued headache, emesis, and a change in mental status. Family members noted somnolence, slowed speech production, and a slow, ataxic gait. Examination was significant for abulia, perseveration, and slowed reaction time with mild improvement of bilateral papilledema seen on funduscopic examination. Routine EEG, repeat MRI brain, magnetic resonance angiogram of the head, and CSF studies, including Lyme serology, were unremarkable, except for an elevated opening pressure of $48 \mathrm{~mm} \mathrm{Hg}$. Screening for drug abuse did not elicit any positive exposures through history and laboratory evaluation.
During the patient's hospitalization, her encephalopathy worsened, with episodes of bowel and bladder incontinence. Long-term EEG monitoring did not show seizures or epileptiform discharges. One month after presentation, repeat MRI brain showed new bilateral abnormal fluid-attenuated inversion recovery/T2 hyperintensity extending along the periventricular regions extending into the centrum semiovale (figure, A, imaging). Dermatology was consulted for areas of skin thickening and discoloration on her ankles, knees, and elbows (figure, B, skin findings), which were considered to be nonspecific and suggestive of retention hyperkeratosis.

Our patient's mental status progressively deteriorated, eventually requiring intubation for airway protection. Six weeks into her disease process, her examination was significant for obtundation, extensive bulbar dysfunction, and flaccid quadriparesis. Serial brain MRIs showed progression of diffuse white matter changes involving the periventricular regions extending into the centrum semiovale, corpus callosum, brainstem, and cerebral peduncles (figure, C, imaging). Magnetic resonance spectroscopy revealed diffuse elevation of lactate throughout the brain, especially in CSF, with pronounced decrease of NAA in right basal ganglia and diffuse elevation of choline. These findings are consistent with a pattern of early leukodystrophy.

\section{Questions for consideration:}

1. What is your new differential diagnosis given these findings?

2. What other questions would you like to ask on history?

3. What other studies should be completed? 
Figure Relevant clinical, imaging, and pathologic findings
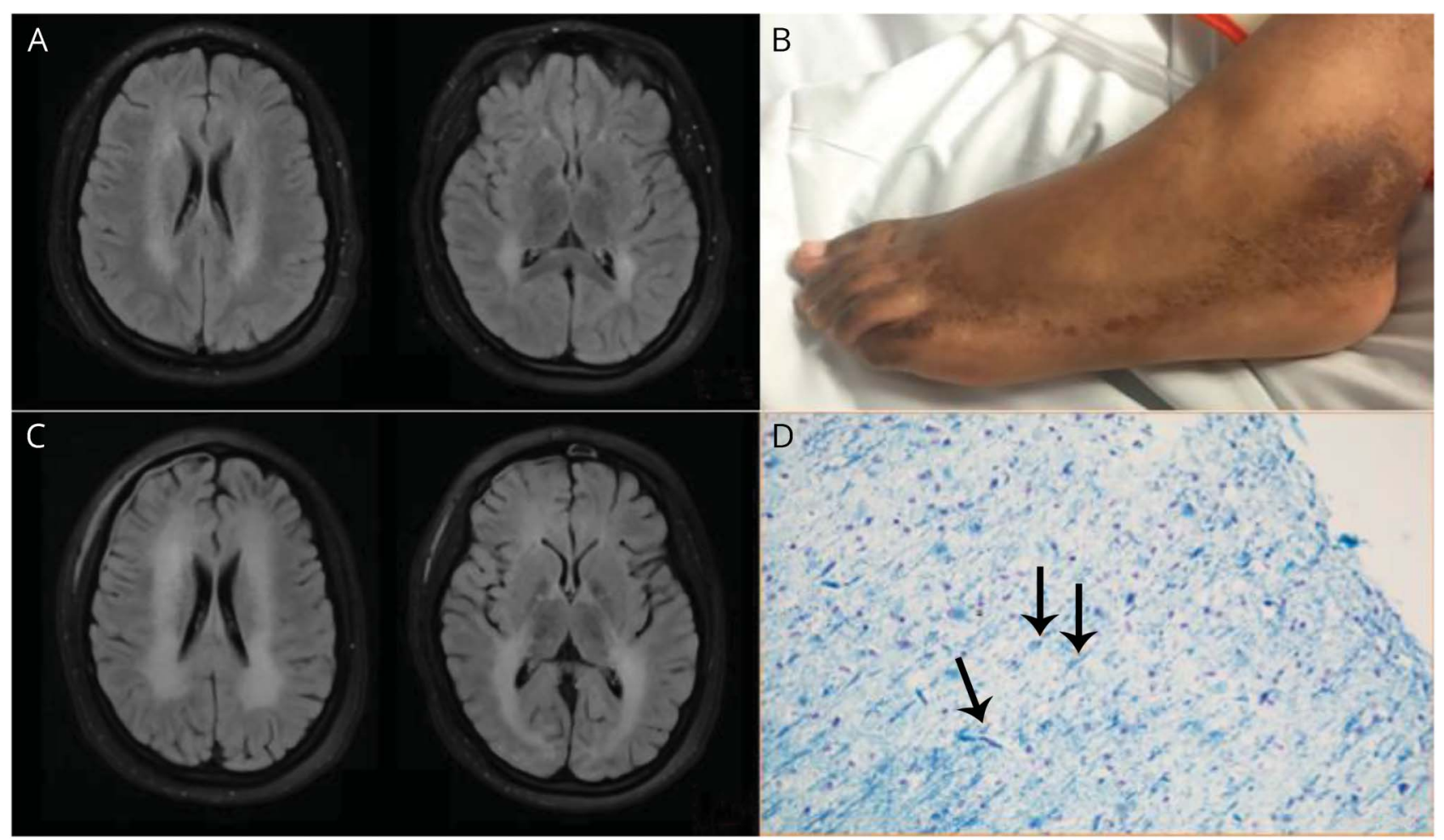

(A) Initial MRI brain shows abnormal fluid-attenuated inversion recovery/T2 hyperintensity extending along the periventricular regions extending into the centrum semiovale. (B) Ichthyotic, hyperpigmented rash involving bilateral feet, knees, forearm, and elbows. (C) Subsequent MRI brain shows progression of diffuse white matter changes involving the periventricular regions extending into the centrum semiovale, corpus callosum, brainstem, and cerebral peduncles. (D) Luxol fast blue-Cresyl violet. Patchy myelin loss with fragmented and ballooned myelin (arrow). Note reactive astrocytes also.

\section{GO TO SECTION 3}




\section{Section 3}

Our patient had new-onset pseudotumor-like syndrome that progressed to frontal lobe and bulbar dysfunction and flaccid quadriparesis, with MRI findings of diffuse symmetric white matter injury consistent with a rapidly progressive leukoencephalopathy. The differential diagnoses of leukoencephalopathy can be divided into 2 separate categories: genetic vs acquired (table). Although rare, genetic leukoencephalopathies may present in adolescence without other features of an underlying metabolic disorder. Acquired causes of leukoencephalopathy include autoimmune disorders, demyelinating disorders, toxic/iatrogenic causes, and infectious or postinfectious disorders.
Extensive workup showed normal vitamin levels and thyroid function and negative autoimmune and infectious evaluations. Whole exome sequencing did not reveal any pathogenic variants related to leukodystrophy or neurodegeneration. The patient underwent brain biopsy of the frontal lobe, which revealed nonspecific reactive astrocytosis and loss of myelin (figure, D, pathology). She was treated with multiple rounds of immunosuppressive agents including IV immunoglobulin, corticosteroids, and plasmapheresis for a presumed autoimmune disorder and did not show improvement with any immunomodulatory therapy.

\section{Question for consideration:}

1. What other etiologies remain on our differential?

Table Etiologies of progressive leukoencephalopathy with juvenile onset

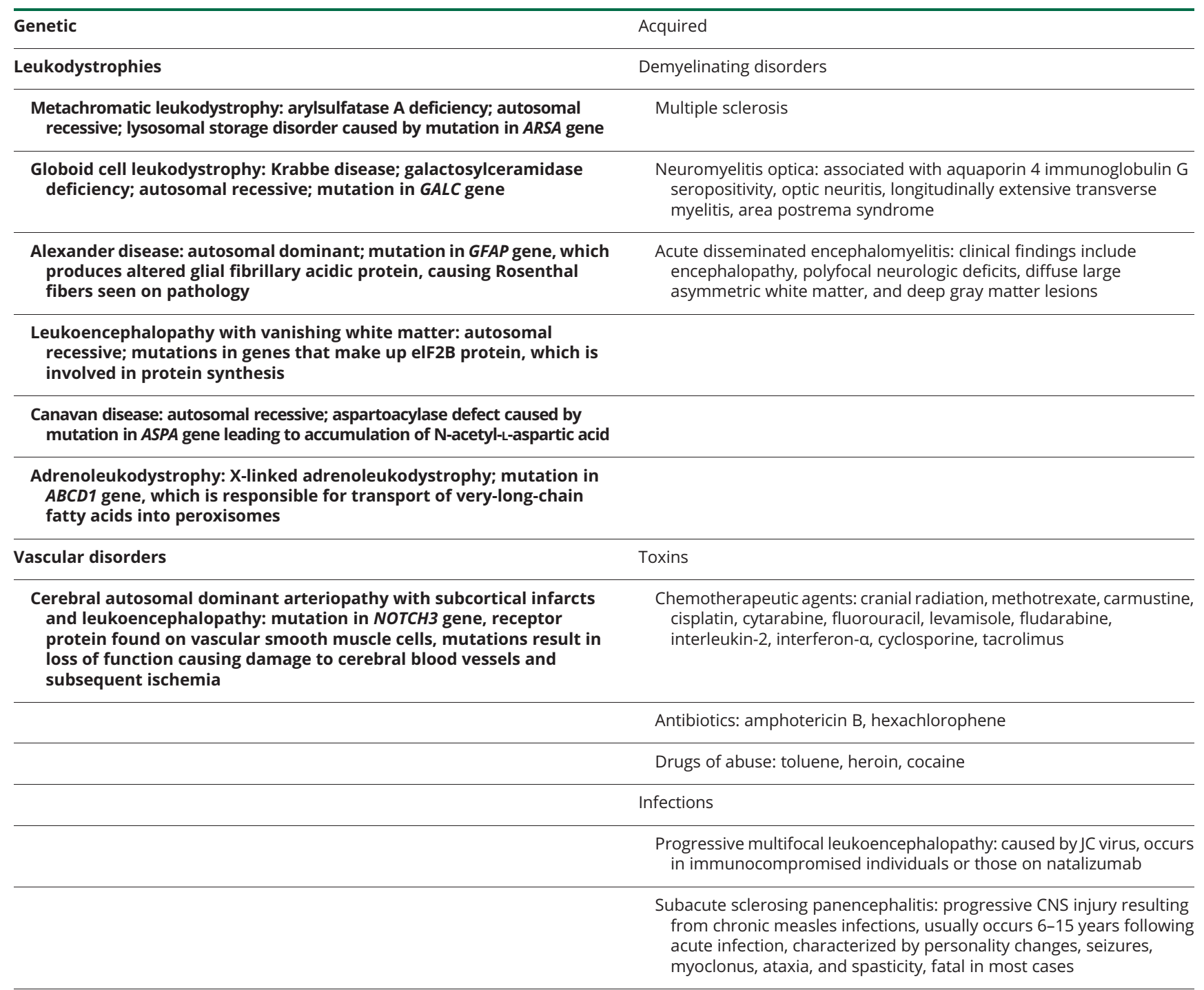

Nutrition

Vitamin $B_{12}$ deficiency: neurologic symptoms include sensory neuropathy, absent reflexes, subacute combined degeneration, developmental regression, hypotonia 


\section{Section 4}

In the absence of a clear autoimmune, demyelinating, infectious, or metabolic process, toxic causes of leukoencephalopathy should be considered. Toxic leukoencephalopathy is usually a diagnosis of exclusion and difficult to elicit without a clear history of exposure. The differential diagnosis of toxic encephalopathy is broad and includes prior medicinal exposures to chemotherapeutic agents, immunosuppressive agents, and antimicrobials, recreational abuse of illicit drugs, and environmental or occupational toxins such as solvents, arsenic, carbon monoxide, or ethylene glycol. ${ }^{2,3}$

With directed questioning, the neurology team elicited a history of significant chronic mothball inhalation. The patient had been using large quantities of mothballs as air fresheners in her poorly ventilated room over many years. Serum paradichlorobenzene (PDCB) level was $2,800 \mu \mathrm{g} / \mathrm{L}$, with the asymptomatic mean reported to be $2.1 \mu \mathrm{g} / \mathrm{L}$. Urine dichlorophenol (DCP) levels were 200,000 $\mu \mathrm{g} / \mathrm{L}$ with asymptomatic mean reported at $200 \mu \mathrm{g} / \mathrm{L}$.

Our patient's clinical history of progressive decline in neurologic status over the course of many months following chronic PDCB exposure, with psychomotor retardation, mutism, bulbar dysfunction, ataxia, an ichthyotic rash, and MRI showing symmetric periventricular white matter hyperintensities, is consistent with PDCB toxicity. In retrospect, normocytic anemia and mildly elevated transaminases, also present since admission, were also consistent with systemic effects of PDCB toxicity. Her serum PDCB and urine DCP levels confirm the diagnosis.

\section{Discussion}

PDCB is a chlorinated aromatic hydrocarbon commonly found in mothballs and toilet bowl fresheners, and is used as an intermediate in the chemical synthesis of pharmaceuticals, fungicides, resins, and dyes. ${ }^{5,6}$ It is a highly volatile compound with a distinctive odor, and is a common indoor air contaminant, resulting in widespread low-level human exposure. PDCB is well-absorbed by ingestion and inhalation, and then rapidly distributed, accumulating primarily in adipose tissue, as well as additional lipophilic sites including the CNS. Significant human toxicity has not been reported from exposure to ambient levels of PDCB, but more substantial acute and chronic exposures have been associated with hepatorenal, pulmonary, hematologic, and neurologic injury. ${ }^{3,5}$ PDCB is a rare cause of neurotoxicity, with only 15 cases reported in the literature. This is the first reported pediatric case of PDCB neurotoxicity with pathologic evidence of white matter injury.

A majority of patients with chronic PDCB exposure present similarly to our case with rapidly progressive alteration in mental status, catatonia, and a flat affect. Examination findings often demonstrate abulia, dysarthria, bradykinesia, hyperreflexia, and ataxia. A notable feature of our case is the documented elevated CSF opening pressure, initially diagnosed as pseudotumor cerebri. One prior case reported "symptoms of intracranial hypertension" ${ }^{7}$ with many others reporting headache at the time of initial presentation. ${ }^{3,8}$ However, elevated CSF opening pressure in association with PDCB exposure has not been reported previously and may explain the etiology of headaches in PDCB-related leukoencephalopathy. In several other cases, non-neurologic manifestations included a dry, ichthyotic rash with hyperpigmentation, ${ }^{3,7}$ normocytic anemia, and acute hepatitis, all of which were seen in our patient.

Serum PDCB and urine DCP levels are useful in diagnosing toxicity if significantly elevated, but these studies usually do not predict the level of toxicity or correlate with severity of exposure. ${ }^{7}$ MRI findings with PDCB toxicity display symmetric periventricular white matter changes with diffusion restriction in areas of acute demyelination. These changes can be delayed following development of symptoms, with 3 case reports initially showing normal imaging., ${ }^{9,10}$ In our case, initial MRI studies were also normal, demonstrating white matter changes on repeat imaging approximately 1 month after initial symptom onset.

PDCB toxicity has been known to cause progressively worsening neurologic deficits and white matter changes on MRI even after removal of the offending agent due to a phenomenon called "coasting." This progressive CNS deterioration in PDCB toxicity is believed to reflect a slow release of the neurotoxin from adipose tissues over time with exacerbations during periods of stress or starvation ${ }^{5}$ presenting as an acute on chronic neurologic decline. Interestingly, our patient did have acceleration of neurologic decline following a 40-pound weight loss while intubated in the intensive care unit as well as while fasting for surgical procedures.

The exact mechanism of cerebral injury from PDCB exposure remains unknown. Some studies suggest oxidative injury as a mechanism of toxicity of PDCB and some of its metabolites. ${ }^{5,6}$ Pathology, in this case, may provide insight into the underlying pathophysiology of brain injury in PDCB exposure. Reactive astrocytosis is a nonspecific finding and can be seen in a variety of toxic injuries. Specific findings of myelin loss on Luxol fast blue-Cresyl violet staining reflects significant injury to myelin sheaths with PDCB exposure and correlates with the predominantly white matter-specific injury seen in our patient. These imaging and pathologic findings argue for an underlying demyelinating pathology, which coincides with the known lipophilic nature of PDCB and remarkable but slow recovery of patients following removal from toxic exposure.

The mainstays of treatment are cessation of exposure and supportive care. Efforts to prevent rapid mobilization of adipose tissue, which might enhance toxin release, have been emphasized. Novel approaches have been proposed as potential therapeutic adjuncts, including IV lipid emulsion (ILE) infusion to enhance removal of highly lipophilic PDCB from brain, and acceleration of hepatic metabolism of PDCB with cytochrome P450-inducing agents such as acetaminophen. ${ }^{5}$ However, we believed that these approaches posed potential 
risks, such as transiently accelerating toxin release from peripheral adipose tissue stores with ILE therapy and exacerbating potential toxicity of some PDCB metabolites with P450 inducing agents. After much deliberation, and in the context of clinical improvement, we decided to forgo trials of experimental therapies in our patient.

This case demonstrates the need for maintaining a broad differential in the diagnosis of potential neurodegenerative conditions and the importance of repeat questioning regarding toxic exposures in histories of patients with leukoencephalopathy, especially as these conditions may be partially reversible with supportive care.

\section{Author contributions}

Payal Patel: case concept and design, primary authorship. Ahmara Ross: authorship of ophthalmology portion. Fredrick Henretig: critical revision of manuscript for intellectual content. Grant Liu: critical revision of manuscript for intellectual content. Brian Harding: provided pathologic images and details, critical revision of manuscript for intellectual content. Jessica Panzer: critical revision of manuscript for intellectual content.

\section{Acknowledgment}

This manuscript is dedicated to the late Jessica Panzer.

\section{Study funding}

No targeted funding reported.

\section{Disclosure}

The authors report no disclosures relevant to the manuscript. Go to Neurology.org/N for full disclosures.

\section{References}

1. Friedman DI, Liu GT, Digre KB. Revised diagnostic criteria for the pseudotumor cerebri syndrome in adults and children. Neurology 2013;81:1159-1165.

2. Filley C, Kleinschmidt-DeMasters BK. Toxic leukoencephalopathy. N Engl J Med 2001;345:425-432.

3. Hernandez S, Wiener S, Smith S. Case files of the New York City poison control center: paradichlorobenzene-induced leukoencephalopathy. J Med Toxicol 2010;6: 217-229.

4. Hill RHJr, Ashley DL, Head SL, Needham LL, Pirkle JL, p-Dichlorobenzene exposure among 1,000 adults in the United States. Arch Environ Health 1995;50:277-280.

5. Dubey D, Sharma V, Pass S, Sawhney A, Stüve O. Para-dichlorobenzene toxicity: a review of potential neurotoxic manifestations. Ther Adv Neurol Disord 2014;7: 177-187.

6. Oikawa S, Kawanishi S, Copper-mediated DNA damage by metabolites of pdichlorobenzene. Carcinogenesis 1996;17:2733-2739.

7. Fueillet L, Mallet S, Spadari M, Two girls with neurocutaneous symptoms caused by mothball intoxication. N Engl J Med 2006;355:423-424.

8. Weintraunb E, Gandhi D, Roninson C. Medical complications due to mothball abuse. South Med J 2000;93:427-429.

9. Avila E, Schreader P, Belliappa A, Faro S. Pica with paradichlorobenzene mothball ingestion associated with toxic leukoencephalopathy. J Neuroimaging 2006;16: 78-81.

10. Reygagne A, Garnier R, Chataigner D, Echene B, Efthymiou ML. Encephalopathy due to repeated voluntary inhalation of paradichlorobenzene. J Toxicol Clin Exp 1992;12: $247-250$.

\section{Subspecialty Alerts by E-mail!}

Customize your online journal experience by signing up for e-mail alerts related to your subspecialty or area of interest. Access this free service by clicking on the "My Alerts" link on the home page. An extensive list of subspecialties, methods, and study design choices will be available for you to choose from-allowing you priority alerts to cutting-edge research in your field!

\section{Neurology in the Spotlight at 2018 Annual Meeting in Los Angeles}

Registration is now open for the totally flexible, dynamic 2018 Annual Meeting. We'll be shining the spotlight on neurology and what you need to excel in your career. Look for the latest science, education, and networking you won't find anywhere else when the biggest names in neurology and neuroscience convene in Los Angeles April 21 through 27. Learn more and register now at $A A N . c o m / v i e w / A M 18$. 


\section{Neurology}

\section{Clinical Reasoning: A 12-year-old girl with headache and change in mental status}

Payal Patel, Ahmara Ross, Fredrick M. Henretig, et al.

Neurology 2018;90;524-529

DOI 10.1212/WNL.0000000000005116

This information is current as of March 12, 2018

\section{Updated Information \&} Services

References

Subspecialty Collections

\section{Permissions \& Licensing}

Reprints including high resolution figures, can be found at: http://n.neurology.org/content/90/11/524.full

This article cites 10 articles, 1 of which you can access for free at: http://n.neurology.org/content/90/11/524.full\#ref-list-1

This article, along with others on similar topics, appears in the following collection(s):

\section{All Pediatric}

http://n.neurology.org/cgi/collection/all_pediatric

Attention

http://n.neurology.org/cgi/collection/attention

Executive function

http://n.neurology.org/cgi/collection/executive_function

Leukodystrophies

http://n.neurology.org/cgi/collection/leukodystrophies

Other toxicology

http://n.neurology.org/cgi/collection/other_toxicology

Information about reproducing this article in parts (figures,tables) or in its entirety can be found online at:

http://www.neurology.org/about/about_the_journal\#permissions

Information about ordering reprints can be found online:

http://n.neurology.org/subscribers/advertise

Neurology ${ }^{\circledR}$ is the official journal of the American Academy of Neurology. Published continuously since 1951, it is now a weekly with 48 issues per year. Copyright @ 2018 American Academy of Neurology. All rights reserved. Print ISSN: 0028-3878. Online ISSN: 1526-632X.

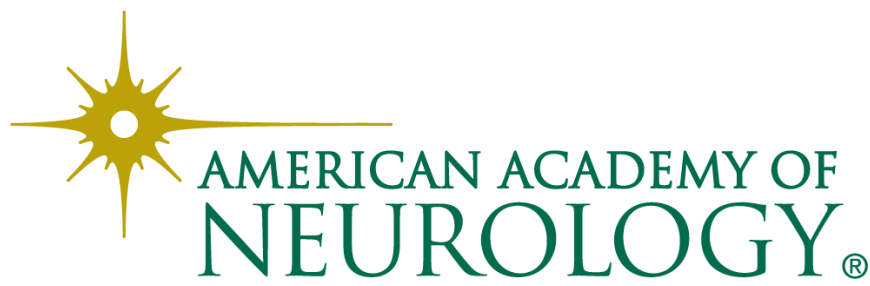

